International Journal of Engineering \& Technology, $7(3.26)(2018) 5-8$
International Journal of Engineering \& Technology
SPC
Website: $\frac{w w w . s c i e n c e p u b c o . c o m / i n d e x . p h p / I J E T}{2}$
Research paper

\title{
Removal of Cadmium (II) by Graphene Oxide-Chitosan Adsorbent from Aqueous Solution
}

\author{
Sepehr Azizkhani ${ }^{1}$, Ebrahim Mahmoudi ${ }^{2}$, Norhafizah Abdullah ${ }^{1}$, M.H. Shah Ismail ${ }^{1}$, A. Wahab Mohammad ${ }^{2}$, Siti Aslina \\ Hussain $^{1} *$ \\ ${ }^{1}$ Department of Chemical and Environmental Engineering, Faculty of Engineering, Universiti Putra Malaysia, 43400 Serdang, \\ Selangor, DE, Malaysia \\ ${ }^{2}$ Department of Chemical and Process Engineering, Faculty of Engineering and Built Environment, Universiti Kebangsaan Malaysia, \\ 43600 UKM Bangi, Selangor, DE, Malaysia \\ *Corresponding author E-mail: aslina@upm.edu.my
}

\begin{abstract}
Pollution has a negative influence on the environment and is necessary to eliminate from wastewater and aqueous solution. There are several adsorbents for removing the pollution, among them Graphene oxide and Chitosan are proper elements with great uptaking ability. In this investigation, graphene oxide surface was coated with chitosan paricles to remove the Cadmium (II) from aqueous solution. The impact of concentration, $\mathrm{pH}$ and time were studied to achieve the optimum conditions of adsorption. The adsorbent was analyzed by TEM, FT-IR, XRD, and SEM analysis. The outcomes presented that the adsorbent was prepared successfully. The concentration item was tested from 10 to $120 \mathrm{ppm}$. The $\mathrm{pH}$ and time items were studied from 3 to 8 value and from 5 to 140 minutes for eliminating cadmium (II) respectively. Freundlich and Langmuir's models was used and the pseudo-second-order was the best fitted kinetic model in this investigation. Conclusively, the maximum adsorption ability of the made adsorbent was achieved at $107.8 \mathrm{mg} / \mathrm{g}$ based on Langmuir isotherm.
\end{abstract}

Key words: Graphene Oxide, Chitosan, Adsorption, Cadmium

\section{Introduction}

Eliminating water contamination is one of the many important issues that begs significant consideration because of severe discharging pollution and metal ions into the environment. Various industries release their effluent including one or several types of pollution and poisonous metal ions (Madadrang et al., 2012). Various pollutants have some negative influences on health and environment such as cadmium (II), lead (II), and copper (II) due to qualities such as non-biodegradable, accumulate tendency and extreme toxicity. Cadmium pollution has unfavorable influence on human health such as diarrhea, kidney damage, lung insufficiency, bones lesions, nausea and renal disturbances (Huang, Wu, Chen, \& Sun, 2015).

Chitosan extracted from chitin has some features such as nontoxicity, hydrophilicity and biodegradable that chelate with heavy metal ions. The chitosan functional groups like hydroxyl and amino groups can interact and combine with pollution and heavy metal ions by chelation or ion exchange (Dubey et al., 2016).

Graphene oxide from oxidizing the graphite and make various oxygen functional groups such as hydroxyl and epoxy functional groups in the basal layer and carboxylic acid groups at the edges of layer (Peng et al., 2017). In this study, graphene oxide was prepared from graphite to improve the hydrophilicity and adsorption capacity of adsorbent. Then, chitosan is combined with graphene oxide to improve the adsorption capacity due to several functional groups and $\pi-\pi$ interaction for removing $\mathrm{Cd}$ (II) from aqueous solution.

\section{Method}

\subsection{Materials}

Graphite powder was achieved from Merck Co. Sulfuric acid and potassium permanganate was provided from Accot Malaysia. Chitosan and Cadmium nitrate were obtained from Sigma Aldrich.

\subsection{Adsorbent Preparation}

In this study, in order to prepare the graphene oxide, graphite powder from Hummers method is used. Graphene oxide were prepared according to the Mahmoudi et al study (Mahmoudi et al, 2015 ) and the $0.4 \mathrm{~g}$ of chitosan was added to $10 \mathrm{~mL}$ of $1 \%(\mathrm{v} / \mathrm{v})$ acetic acid solutions and let stirred around $8 \mathrm{hr}$. Then, $0.4 \mathrm{~g}$ chitosan quantity was added to the fixed amount of graphene oxide $(1 \mathrm{~g})$ and stirred around $3 \mathrm{hr}$ at $50 \mathrm{C}^{\circ}$.

\section{Experimental}

\subsection{Adsorption Study}

In this study, some effective parameters such as initial concentration, $\mathrm{pH}$, contact time and temperature, were tested. The amount of $0.1 \mathrm{~g} \mathrm{GO}-\mathrm{Ch}$ was added to $\mathrm{Cd}$ (II) solutions in various initial concentrations with $50 \mathrm{ml}$ of synthetic Cd (II) solution and adsorption capacity is measured. PH effect for eliminating of $\mathrm{Cd}$ (II) from aqueous solution was studied from 3 to 8 value in the optimum initial concentration. The effect of contact time was 
observed from 5 to 140 minutes at $\mathrm{pH} 7$ and initial concentration of $20 \mathrm{mg} / \mathrm{l}$.

Equation 1 shows the adsorption percentage of Cd (II):

$q \%=\frac{\left(\mathrm{C}_{0}-\mathrm{C}_{\mathrm{e}}\right)}{\mathrm{C}_{0}} \times 100 \%$

\section{Results and Discussion}

\subsection{Adsorbent Characterization}

\subsubsection{FT-IR Analysis}

The FT-IR of GO-Ch composite was tested and has shown in the figure 1. According to the FT-IR test it can be seen that, the peaks at $3450,1367,1066 \mathrm{~cm}^{-1}$ illustrate the main functional groups of graphene oxide. the peaks of 3546,1622 and $1543 \mathrm{~cm}^{-1}$ prove the stretching and vibration between the amine groups of chitosan and oxygen functional groups of graphene oxide (Ge \& Ma, 2015).

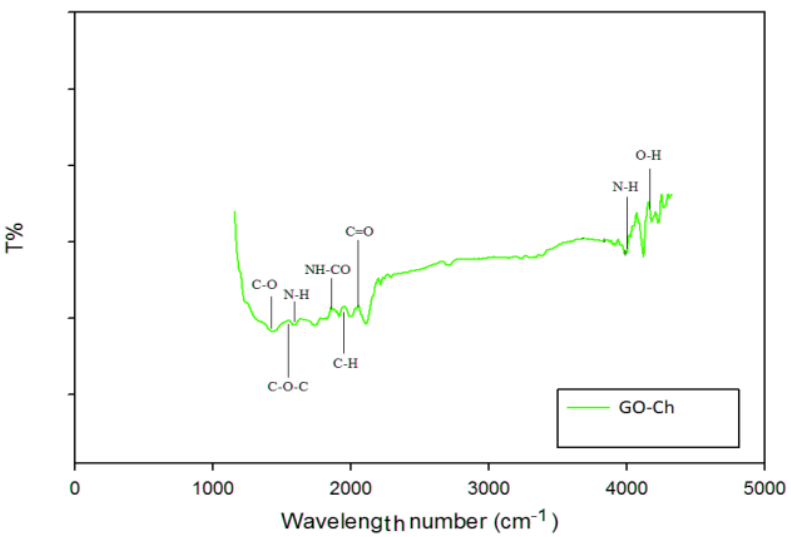

Fig 1: Adsorbent Characterizations of GO-Ch using FT-IR spectroscopy analysis

\subsubsection{TEM Analysis}

The TEM of graphene oxide-chitosan has been shown in the Figure 2. The smooth layer in Figure 2(a) shows the graphene oxide sheet. Figure 2(b) confirmed the chitosan particles were coated and mixed on the graphene oxide sheet.
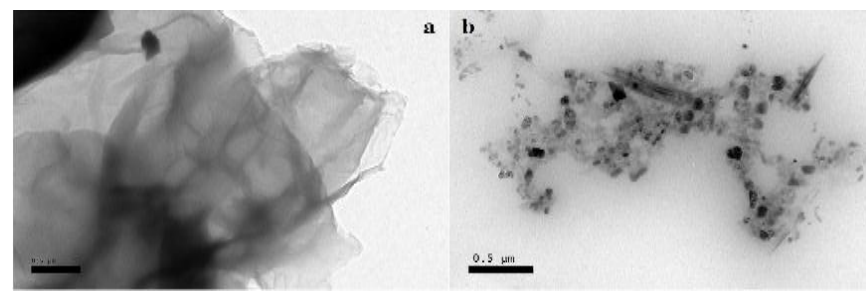

Fig 2: Characterization analysis of (a) graphene oxide (b GO-Ch using TEM methods

\subsubsection{SEM Analysis}

Graphene oxide and graphene oxide-chitosan are shown in the Figure 3. Figure 3(a) shows the smooth sheet of graphene oxide and in Figure 3(b) the rough surface shows the mixing or coating of graphene oxide with chitosan particles.

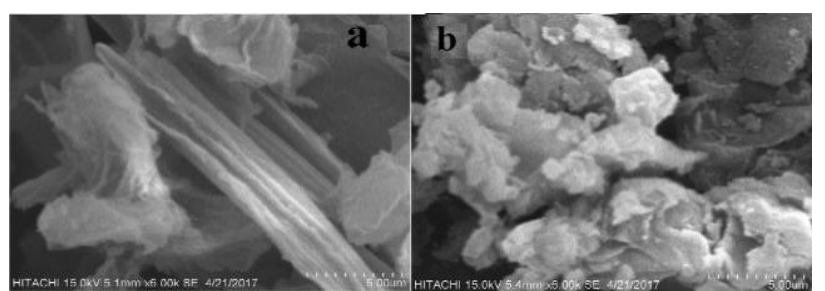

Fig 3: Characterization analysis of (a) graphene oxide sheets (b) GO-Ch using SEM

\subsubsection{XRD Analysis}

Graphene oxide-chitosan XRD is shown in the Figure 4. Graphene oxide has one peak at around 10 degree $2 \theta$ (Xue et al., 2016). By combining the chitosan with graphene oxide, the intensity of peak 10 degree $2 \theta$ decreased and some peaks appear at 45.12 and 53.7 appear. The peaks change shows the interaction between graphene oxide with chitosan particles. The peaks at 45.12 and 53.7 explain the hydrogen bonding interaction of chitosan particles (Ray et al., 2010).

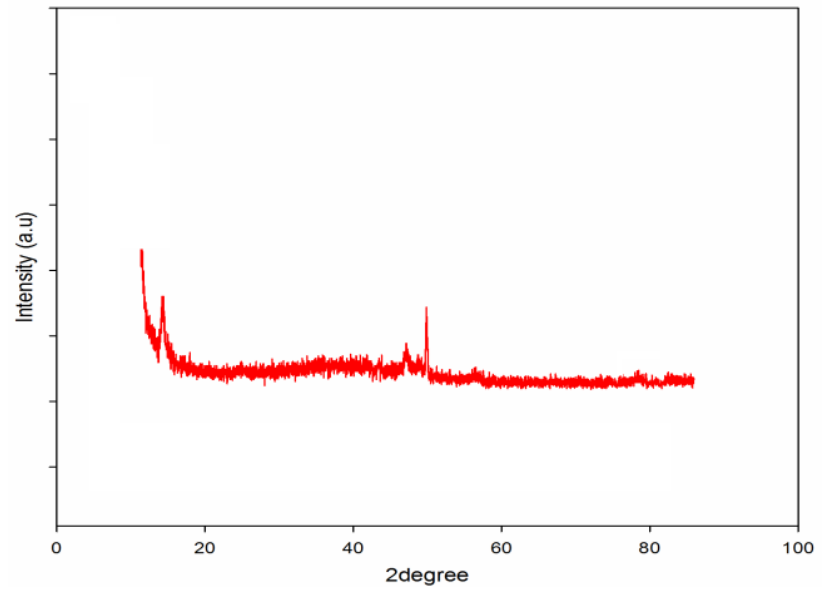

Fig 4: Characterization analysis of graphene oxide and GO-Ch using XRD

\subsection{Adsorption Experiments}

\subsubsection{Effect of Initial Concentration}

The optimization to identify the suitable amount of an adsorbent to adsorb heavy metal ions was accomplished for Cd (II). In order to obtain the optimum initial concentration, 7 initial concentrations for Cd (II) in the range of $10 \mathrm{mg} / \mathrm{l}, 20 \mathrm{mg} / \mathrm{l}, 40 \mathrm{mg} / \mathrm{l}, 60 \mathrm{mg} / \mathrm{l}, 80$ $\mathrm{mg} / \mathrm{l}, 100 \mathrm{mg} / \mathrm{l}$ and $120 \mathrm{mg} / \mathrm{l}$ were considered. The outcomes of Cd (II) adsorption are displayed in the Figure 5. It is usually determined that the maximum $\mathrm{Cd}$ (II) elimination is at $10 \mathrm{mg} / \mathrm{l}$. The binding sections are filled by metal ions immediately and as a consequence, there is no additional adsorption. At higher initial concentration, the adsorption capacity decreased maybe because of larger adsorbent surface area.

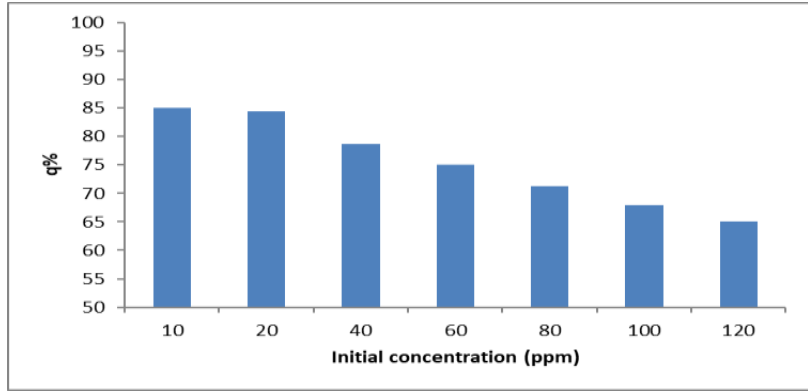

Fig 5: Adsorption capacities of $\mathrm{Cd}$ (II) by GO-Ch in several initial concentrations

\subsubsection{Effect of $\mathrm{pH}$}

The $\mathrm{pH}$ effects for adsorbing Cd (II) were investigated in the range of 3.0-8.0 and the outcomes are displayed in the Figure 6. In the first $\mathrm{pH}$ ranges of adsorption methods, the adsorption of $\mathrm{Cd}$ (II) rises with a $\mathrm{pH}$ increasing till $\mathrm{pH} 6$ for $\mathrm{Cd}$ (II) and then decreased. Consequently, the rest adsorption tests were conducted at pH 6.0 for Cd (II). This Cd (II) adsorption may be due to some reasons like complex adsorbent surface, electrostatic interaction and graphene oxide and chitosan functional groups such as amine, hydroxyl and carboxyl. 


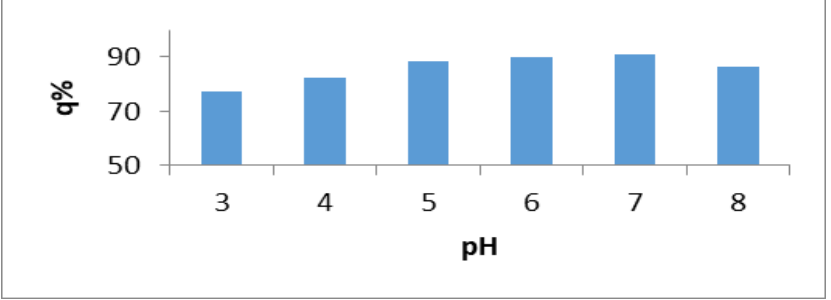

Fig 6: Adsorption capacities of $\mathrm{Cd}$ (II) by GO-Ch in several pHs

\subsubsection{Effect of Contact Time}

The effect of contact time has the influence on a number of heavy metal ions adsorption. In this study, the adsorption capacities are measured 9 times in the range of 5 to 140 minutes for Cd (II) in their optimum situation. According to Figure 7, the adsorption $\mathrm{Cd}$ (II) rose rapidly in the first 40 minutes, followed by slow increase till 60 minute and reached equilibrium from 60 minutes. The surface of adsorbent was free in primary contact time and the removal percentage suddenly increased due to available sites, but with passing time, the active binding sites and functional groups of adsorbent were getting occupied and adsorption capacity increased slowly till it remained constant (Du et al., 2014).

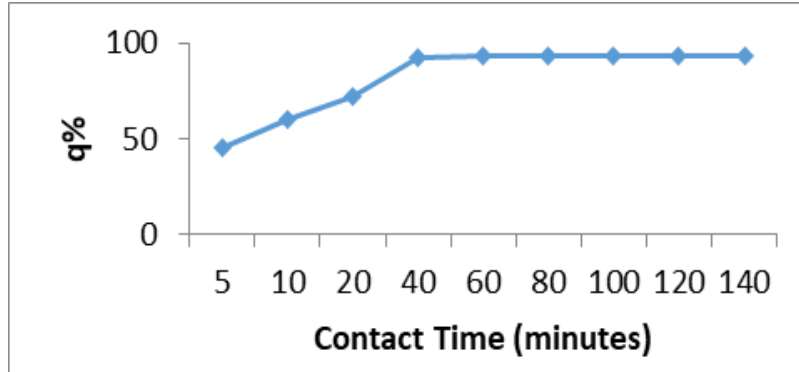

Fig 7: Adsorption capacities of Cd (II) by GO-Ch in several times

\subsection{Adsorption Isotherms}

Isotherm models are analytical and mathematical patterns to explain the diffusion and concentration of the pollution within the solution and adsorbent phases. Also, adsorption isotherm models are important to demonstrate the adsorbent ability and efficiency. In this investigation, Freundlich, Langmuir, and Temkin (Monier \& Latif, 2012) were applied to the experimental results and their parameters are shown in Table 1.

Table 1: Isotherm models parameters and values for adsorbing Cd (II) by GO-Ch

\begin{tabular}{ccc}
\hline Models & Parameters & Cd (II) \\
\hline \multirow{2}{*}{ Freundlich } & $\mathrm{k}(\mathrm{mg} / \mathrm{g})$ & 2.35 \\
& $\mathrm{Q} \mathrm{max}(\mathrm{mg} / \mathrm{g})$ & 25.22 \\
& $\mathrm{R}^{2}$ & 0.99 \\
& $\mathrm{~b}(\mathrm{l} / \mathrm{mg})$ & 0.0052 \\
Langmuir & $\mathrm{Rl}$ & 0.86 \\
& $\mathrm{Q} \max (\mathrm{mg} / \mathrm{g})$ & 107.8 \\
& $\mathrm{R}^{2}$ & 0.93 \\
Temkin & $\mathrm{A}(1 / \mathrm{g})$ & 62.12 \\
& $\mathrm{~b}$ & 0.85 \\
& $\mathrm{R}^{2}$ & 0.94 \\
\hline
\end{tabular}

Regarding the constants, special $\mathrm{R}^{2}$ values displayed in table 1 are based on the fitted isotherm models of adsorbing Cd (II) by GOCh were Temkin, Freundlich, and Langmuir (Monier \& Latif, 2012) with $R^{2}$ values of $0.94,0.99$ and 0.93 respectively. In this study, the Q max of Cd (II) adsorption was $107.8 \mathrm{mg} / \mathrm{g}$ calculated by Langmuir model.

\subsection{Kinetics Study}

Kinetic models are important to determine the mass transport and adsorption mechanism for using the experimental result. The kinetic values and the related constant models of pseudo-first- order, pseudo second-order and Elovich were achieved by applying the linear regression.

Table 2: Kinetic model parameters obtained in the adsorption of $\mathrm{Cd}(\mathrm{II})$ using GO-Ch

\begin{tabular}{lll}
\hline Models & Parameters & \multicolumn{1}{c}{$\mathrm{Cd}(\mathrm{II})$} \\
\hline pseudo-first-order & $\mathrm{K}\left(\mathrm{h}^{-1}\right)$ & 0.00031 \\
& $\mathrm{R}^{2}$ & 0.54 \\
pseudo-second-order & $\mathrm{K}\left(\mathrm{gmg}^{-1} \mathrm{~h}^{-1}\right)$ & 0.023 \\
& $\mathrm{Q}(\mathrm{mg} / \mathrm{g})$ & 10.26 \\
Elovich & $\mathrm{R}^{2}$ & 0.99 \\
& $\dot{\alpha}(\mathrm{mg} /(\mathrm{g} \mathrm{min}))$ & 11.47 \\
& $\beta(\mathrm{g} / \mathrm{mg})$ & 0.48 \\
& $\mathrm{R}^{2}$ & 0.91 \\
\hline
\end{tabular}

According to Table2, it can be seen that pseudo-second-order are based on fitted kinetic models for adsorbing Cd (II) by GO-Ch with the R2 value of 0.99 . Pseudo-second order kinetic model assumed that the process was chemisorption which means the adsorption occurred through participation of the chemisorptive bond or electron exchanging between $\mathrm{Cd}$ (II) and GO-Ch.

\section{Conclusion}

Heavy metals have negative effects on the eco-system and health and it is necessary to eliminate effluent from wastewater and aqueous solution. Adsorption technique is the appropriate method to eliminate this pollution. In this study, the TEM, SEM, XRD and FT-IR of GO-Ch adsorbent were analyzed. The FT-IR peaks explained the joining of chitosan with graphene oxide, also, TEM, SEM showed a constant dispersal of chitosan element on the surface of graphene oxide. The maximum adsorption uptake of $\mathrm{Cd}$ (II) which is obtained from Langmuir was $107.8 \mathrm{mg} / \mathrm{g}$ by GO-Ch and fitted well with the pseudo-second-order kinetic model.

\section{Acknowledgment}

This research was supported by University Putra Malaysia (UPM) according to the grant number of 9502700 and Universiti Kebangsaan Malaysia (UKM). We thank our colleagues who provided insight and expertise that greatly assisted the research, although they may not agree with all of the interpretations of this paper.

\section{Reference}

[1] Du, Q., Sun, J., Li, Y., Yang, X., Wang, X., Wang, Z., \& Xia, L. (2014). Highly enhanced adsorption of congo red onto graphene oxide/chitosan fibers by wet-chemical etching off silica nanoparticles. Chemical Engineering Journal, 245, 99-106. https://doi.org/10.1016/j.cej.2014.02.006

[2] Dubey, R., Bajpai, J., \& Bajpai, A. K. (2016). Chitosan-alginate nanoparticles (CANPs) as potential nanosorbent for removal of $\mathrm{Hg}$ (II) ions. Environmental Nanotechnology, Monitoring and Management, 6(Ii), 32-44. https://doi.org/10.1016/j.enmm.2016.06.008

[3] Ge, H., \& Ma, Z. (2015). Microwave preparation of triethylenetetramine modified graphene oxide/chitosan composite for adsorption of $\mathrm{Cr}(\mathrm{VI})$. Carbohydrate Polymers, 131, 280-287. https://doi.org/10.1016/j.carbpol.2015.06.025

[4] Huang, J., Wu, Z., Chen, L., \& Sun, Y. (2015). Surface complexation modeling of adsorption of $\mathrm{Cd}(\mathrm{II})$ on graphene oxides. Journal of $\begin{array}{llll}\text { Molecular } & \text { Liquids, } & \text { 753-758. }\end{array}$ https://doi.org/10.1016/j.molliq.2015.06.047

[5] Madadrang, C. J., Kim, H. Y., Gao, G., Wang, N., Zhu, J., Feng, H., Hou, S. (2012). Adsorption behavior of EDTA-graphene oxide for $\mathrm{Pb}$ (II) removal. ACS Applied Materials and Interfaces, 4(Ii), 11861193.

[6] Mahmoudi, E., Ng, L. Y., Ba-Abbad, M. M., \& Mohammad, A. W. (2015). Novel nanohybrid polysulfone membrane embedded with silver nanoparticles on graphene oxide nanoplates. Chemical $\begin{array}{lll}\text { Engineering } & \text { Journal, } & \text { 277, }\end{array}$ https://doi.org/10.1016/j.cej.2015.04.107

[7] Monier, M., \& Abdel-Latif, D. A. (2012). Preparation of cross-linked magnetic chitosan-phenylthiourea resin for adsorption of $\mathrm{Hg}$ (II), $\mathrm{Cd}$ (II) and $\mathrm{Zn}$ (II) ions from aqueous solutions. Journal of Hazardous Materials, 209-210, 240-249. 
https://doi.org/10.1016/j.jhazmat.2012.01.015

[8] Peng, W., Li, H., Liu, Y., \& Song, S. (2017). PT Hubei Key Laboratory of Mineral Resources Processing and Environment, Wuhan Hubei Provincial Collaborative Innovation Center for High Efficient Utilization of. Journal of Molecular Liquids. https://doi.org/10.1016/j.molliq.2017.01.064

[9] Ray, M., Pal, K., Anis, a., \& Banthia, a. K. (2010). Development and Characterization of Chitosan-Based Polymeric Hydrogel Membranes. Designed Monomers \& Polymers, 13(3), 193-206. https://doi.org/10.1163/138577210X12634696333479

[10] Xue, X., Xu, J., Baig, S. A., \& Xu, X. (2016). Synthesis of graphene oxide nanosheets for the removal of $\mathrm{Cd}(\mathrm{II})$ ions from acidic aqueous solutions. Journal of the Taiwan Institute of Chemical Engineers, 59, 365-372. https://doi.org/10.1016/j.jtice.2015.08.019 